\title{
Frutales y agroindustria: conservas, aceites y maderas (Chile y Cuyo, 1550-1850)
}

\begin{abstract}
por
Pablo Lacoste. Universidad de Santiago de Chile (USACH) / José Antonio Yuri. Centro de Pomáceas de la Universidad de Talca / Marcela Aranda (USACH) / Amalia Castro. Universidad Católica Silva Henríquez / Katherine Quinteros, Mario Solar, Natalia Soto y Cristián Chávez ${ }^{1}$
\end{abstract}

La rápida propagación de plantas frutales europeas en Chile y Cuyo formuló el problema de su aprovechamiento, asunto complejo antes de la disponibilidad de medios de refrigeración. La respuesta fue el impulso a la actividad agroindustrial. Algunos frutas se conservaban mediante deshidratación, otras se usaban para elaboraban aceites. Algunos de estos productos se comercializaban en el mercado interno y otros se exportaban, particularmente al Perú. Además se avanzó en el aprovechamiento de frutales tanto para construcción como en carpintería y ebanistería. Estas actividades aseguraron la viabilidad económica de la fruticultura e hicieron posible su expansión en la región estudiada.

Palabras Clave: Agroindustria; fruticultura; deshidratación de fruta; aceite de oliva.

Chile se ha convertido en una potencia exportadora de fruta. Con solo 324.000 hectáreas plantadas (2007), sus exportaciones alcanzaron a US\$ 3.342 millones FOB, cifra significativa para una economía del tamaño de este país. En el Hemisferio Sur, Chile es el mayor exportador de uvas, manzanas, ciruelas, duraznos y cerezas; en el orden mundial, ocupa el 1. er lugar en cirue-

1 Pablo Lacoste es profesor titular de la Universidad de Santiago de Chile (USACH). José Antonio Yuri es ingeniero agrónomo, profesor titular y director del Centro de Pomáceas de la Universidad de Talca; Marcela Aranda es posdoctoranda USACH; Amalia Castro es profesora de la Universidad Católica Silva Henríquez; Katherine Quinteros, Mario Solar, Natalia Soto y Cristián Chávez son ayudantes del proyecto Fondecyt 1080210. Contacto: pablo.lacoste@usach.cl. 
las y uvas; el $4 .^{\circ}$ en manzanas, el $5 .^{\circ}$ en duraznos y el $6 .^{\circ}$ en peras. Chile es, sin duda, uno de los grandes actores de la fruticultura mundial.

La fruticultura no es una actividad nueva en Chile, pues tiene una tradición de casi 500 años, iniciada a partir de la llegada de los colonizadores españoles. A lo largo de la época colonial, los hispanocriollos incorporaron las plantas frutales europeas, las adaptaron a los suelos y climas americanos e iniciaron su expansión por todo el Reino. Sin embargo, en los primeros siglos, los fruticultores chilenos se encontraron con un problema técnico: la ausencia de medios de conservación y de transporte adecuados a las características de la fruta. En este contexto, las buenas condiciones de clima y suelo que Chile ofrecía para la expansión de esta actividad, entraban en colisión con la fragilidad del producto. Por lo tanto, la fruticultura solo era viable en la medida que se resolvía este problema mediante el trabajo que permitiera un aprovechamiento de las plantas, sobre todo la elaboración y conservación de sus frutos.

El cultivo de plantas europeas en América a partir del siglo XV ha dado lugar a importantes debates historiográficos. Crosby teorizó sobre el «imperialismo ecológico» ${ }^{2}$ mientras que Gligo ${ }^{3}$ desarrolló la noción de «expoliación» postcolombina. También se ha planteado el problema de «la conquista biológica del Nuevo Mundo» ${ }^{4}$. Allí donde los parámetros ecológicos recordaban el Mediterráneo o la Europa Templada, nuevos ecosistemas agrícolas de origen europeo sustituían a los paisajes originales: el centro de Chile, por ejemplo, fue 1lamado «la Italia de Sudamérica» ${ }^{5}$.

La introducción de nuevas plantas y animales fue acompañada por la implantación de nuevos modos y relaciones de producción, signadas por el predominio del latifundio desde México hasta las pampas rioplatenses ${ }^{6}$. El latifundio fundado en la producción agropecuaria extensiva, fue el modelo dominante en América Latina, pero no el único. Convivió con otros modos de producción que tuvieron diferentes implicancias sociales y económicas. En este campo, un papel especial cupo a la fruticultura que, dado su carácter de agricultura intensiva, generó otras posibilidades de desarrollo, sobre todo para los pequeños propietarios. Fernand Braudel detectó este fenómeno para algunas regiones de Francia, sobre todo por el cultivo de las viñas? ${ }^{7}$. Un fenómeno análogo ha comenzado a observarse en algunas regiones de América Latina,

2 Crosby [1986], 1988.

3 Gligo, 1980; 2001.

4 Melville, 1999.

5 Alonso Millán, 2010.

6 Chevalier, 1956; Mellafe, 1981; Hernández y Romano, 1999; Halperín Donghi, 2008.

7 Braudel, 1986: 100-101. 
particularmente en las zonas donde las condiciones naturales y culturales hicieron posible el desarrollo de estos cultivos y su consiguiente desarrollo agroindustrial $^{8}$.

Menor atención han merecido las demás plantas frutales. Ello se debe, en parte, a la magnitud: ninguna alcanzó las dimensiones de la vid y el vino. Además, la problemática de la historia de las frutas en el tiempo estudiado, no ha estado en el main stream de la historiografía central. Ello se debe, en buena medida, al escaso papel que tuvo la fruta en Europa medieval, y su lento despertar después del Renacimiento. En realidad, Europa Medieval tuvo un polo frutícola importante, pero no estaba en sus centros de poder, sino en su periferia geográfica y política: Al Andalus. Los musulmanes introdujeron con éxito las plantas frutales y su cultura. Ellos cultivaron sus huertos y jardines, estudiaron sus características y las dieron a conocer a través de sus tratados de botánica y agronomía ${ }^{9}$. Aprendidos por los españoles, estos conocimientos llegaron también a América. Los pueblos hispanocriollos del Reino de Chile se apropiaron de esas nociones, y las llevaron a la práctica, con sus propios criterios.

El presente artículo pretende explorar un aspecto que todavía no ha sido incorporado al debate académico: la forma de desarrollo de la fruticultura en Chile y la consiguiente emergencia de un espacio de agricultura intensiva, pequeña propiedad y mayor movilidad social. Explicar la existencia de la fruticultura implica resolver varios problemas. Sobre todo se requiere detectar la racionalidad de esta actividad, teniendo en cuenta el corto tiempo de conservación de la fruta madura después de la cosecha, en el contexto de un mercado interno pequeño, y antes de la disponibilidad de medios de refrigeración y transporte modernos para alcanzar mercados distantes.

La base del proceso agroindustrial al que se hace referencia al comienzo del artículo se encuentra en la abundancia de frutas en Chile y Cuyo. Por ello, el primer paso de esta investigación fue identificar qué plantas se cultivaban en la región estudiada, en qué cantidades y proporciones. Para avanzar en esa dirección se realizó un relevamiento de los registros notariales y judiciales de las jurisdicciones de La Serena, San Felipe, Santiago, San Fernando, Cauquenes, Parral, Mendoza y San Juan. A partir de estos datos se reconstruyó una suerte de geografía de la fruta en Chile y Cuyo, para el periodo 1700-1850. Los registros compulsados señalaron la existencia de 109.366 plantas frutales. Estas tenían cinco niveles de jerarquía según la recurrencia:

8 Mishkin, 1975; Amaral, 1990; Muñoz, 2001; Corona Páez, 2004; Rice, 2010; Coria, 2010; Lacoste, 2004; 2007; 2008; Soldi, 2006; Rivera Medina, 2006.

9 Carabaza Bravo, García Sánchez et al., 2004. 
muy abundante (13.000 a 40.000 ejemplares), abundante (6.000-9.000), intermedia (2.000-3.500), escasa (100-500) y muy escasa (5 a 99). Las especies muy abundantes eran el duraznero (38.588 árboles), el almendro (14.781), el peral (14.033) y el manzano (13.484). Las plantas de recurrencia abundante eran el olivo (8.282) y la higuera (6.047). Las de recurrencia intermedia eran ciruelos (3.323), membrilleros (2.377), nogales (2.076), guindos (2.046) y naranjos (1.963). Los frutales escasos eran damascos (454), granados (356), limoneros (334), limos (193) y chirimoyos (115). Los muy escasos eran los cidros (52), lúcumos (49), cerezos (10) y castaños (5).

\section{FrutALES EN CHILE Y CUYO}

Distribución Geográfica de Plantas

La Serena, San Felipe, Santiago, San Fernando, Parral, Cauquenes, San Juan y Mendoza (1700 - 1860)

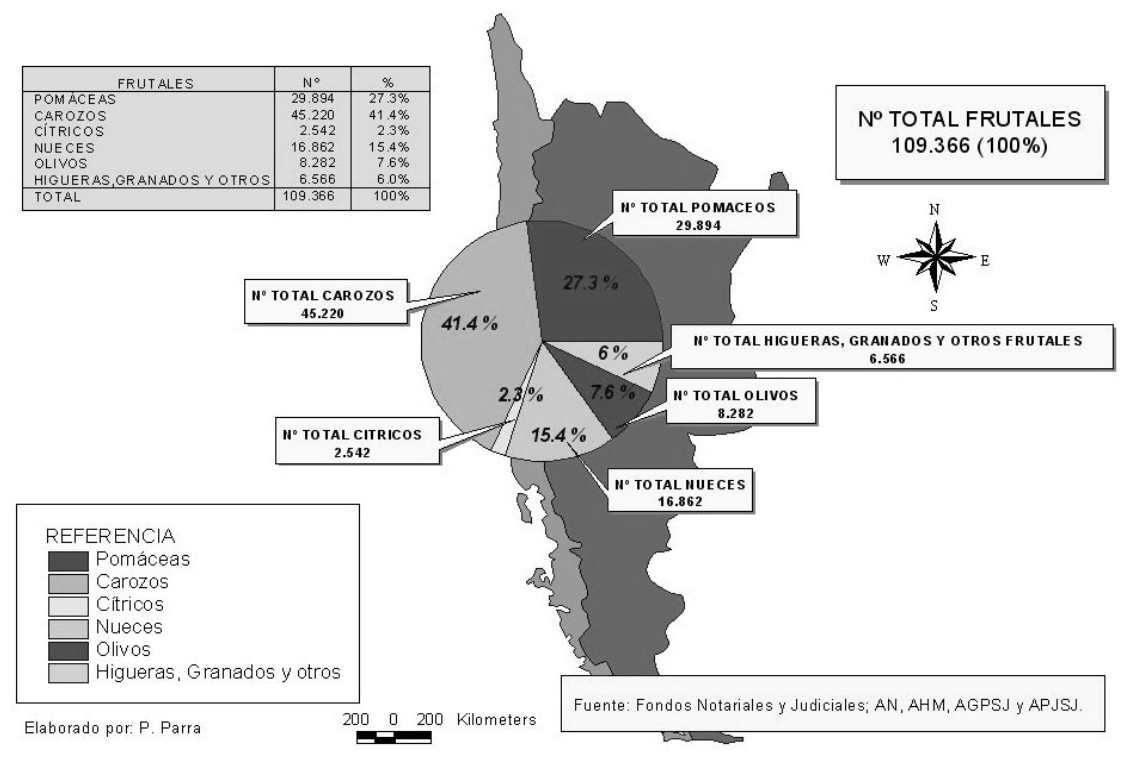

Si bien cultivaron 20 plantas distintas, los fruticultores chilenos se especializaron en seis de ellas: durazneros, manzanos, perales, almendros, olivos e higueras. De estas seis especies, se registraron 95.215 ejemplares, lo cual representaba el $87 \%$ del total de plantas frutales. Las otras catorce especies apenas reunían 14.019 árboles, correspondientes al 12\%. Las seis especies principales centraron la atención de los fruticultores chilenos y cuyanos y, por lo tanto, el presente estudio se focalizó principalmente en ellas. De allí la necesidad de 
examinar la producción de deshidratados de duraznos, manzanas, peras e higos, juntamente con la elaboración de aceites de oliva y almendra y el aprovechamiento de su madera en la construcción, carpintería y ebanistería. La explotación de esas plantas sería la base para construir la matriz general de toda la agroindustria basada en frutas de la región estudiada. Pero antes de abordar directamente los datos producidos en la investigación de archivo, conviene considerar el contexto general dentro del cual trabajaron los fruticultores hispanocriollos de Chile y Cuyo. Y ello remite a las ideas que traían consigo los colonizadores que llegaron de la península ibérica. Respecto al sistema de pesas y medidas, este trabajo utiliza las unidades de la época ${ }^{10}$.

\section{APROVECHAMIENTO DE LAS FRUTAS EN LOS MANUALES HISPANOÁRABES Y ESPAÑOLES}

La abundancia de las plantas frutales en la península ibérica, impulsada por la presencia de los musulmanes, generó la necesidad de optimizar su aprovechamiento. El tema está presente en los tratados de los botánicos y agrónomos andalusíes ${ }^{11}$, como así también en los tratados españoles posteriores ${ }^{12}$. Posteriormente se elaboraron otros manuales de agricultura ${ }^{13}$, en los cuales no hubo mayores progresos en lo referente a las técnicas de conservación de fruta. Por lo tanto, las recomendaciones del fray Agustín conservaron una posición de liderazgo por largo tiempo.

Los tratados andalusíes destacaban el valor de los higos por sus aportes nutritivos, tanto para alimentar personas como ganados. Los textos entregan métodos de conservación de los higos, incluyendo recomendaciones de secarlos en julio y consumirlos en diciembre ${ }^{14}$. También se recomiendan técnicas de deshidratación para conservar ciruelas, peras y duraznos. La pulpa de este último se cortaba en anillos, se secaba al sol, y luego se guardaba en recipientes, preferentemente vasijas embreadas; previo a su consumo, debían rociarse con agua $^{15}$. Para deshidratar las ciruelas, se les hacían cortes antes de ponerlas a se-

10 La unidad de medida para líquidos era la arroba, equivalente a 36 litros. Las unidades de peso eran la libra (460 gramos), la arroba (1 @ = 25 libras =11,5 kg), el almud $(=8,62 \mathrm{~kg})$ y la fanega ( $=9$ arrobas $=12$ almudes $=103,5 \mathrm{~kg})$. La unidad monetaria era el peso de ocho reales. Las unidades de longitud eran la vara $(1 \mathrm{v}=0,83$ metros $)$.

11 Carabaza Bravo, García Sánchez et al., 2004.

12 Agustín, 1617.

13 Travanet, 1848; Sandalio Arias, 1856.

14 Carabaza Bravo y García Sánchez, 2004: 94.

15 Ibidem: 166. 
car al sol y antes de guardarlas, se rociaban con miel aguada; de esta forma se obtenían las llamadas «ciruelas pasas» ${ }^{16}$. Las peras también se podían conservar por un tiempo considerable sin deshidratarse, mediante cuidadas técnicas de guarda basadas en el uso de hojas de adelfa ${ }^{17}$. Con respecto a las manzanas y los membrillos, se recomiendan técnicas de guarda, pero no de deshidratación ${ }^{18}$.

La herencia musulmana contribuyó sensiblemente a las ideas que luego transmitieron los tratadistas españoles, tanto en técnicas de guarda como en deshidratación. De todos modos, se añadieron algunos enfoques de interés. En primer lugar se recomendaba priorizar el cultivo de pomáceas sobre los carozos, dada la mayor durabilidad de su fruta: se podían conservar hasta la primavera con cuidados relativamente sencillos. Se sugería cosechar las manzanas y peras en luna en cuarto menguante, cuidar que no se machuquen y almacenarlas en lugar seco y fresco; se podían cubrir con paja o con capullos de hiel de lagarto verde ${ }^{19}$. Mayor trabajo requería la conservación de otras frutas como higos y carozos. El texto señalaba al respecto:

consérvanse los higos secos mucho tiempo si los metéis en unos cestos en el horno después que este ha cocido el pan y después, poniéndolos en vaso que no esté envidriado; más conviene cogerlos con el pezón, con el cual se tienen en el árbol, poniéndolos al sol, rociándolos con agua salada, mezclada con aceite hirviendo, tapado muy bien dicho vaso, con lodo o barro, porque no respire por ninguna parte ${ }^{20}$.

En relación con la conservación de los duraznos, el texto recomendaba lo siguiente: «sus frutas se conservan con agua salada o con vinagre dulce, sacándoles primero los huesos y secos conforme los higos. Otros los conservan con azúcar o miel» ${ }^{21}$. De acuerdo al autor, las cerezas y guindas se cosechan a la salida del sol y se conservan «secas al sol, y cocerlas con el zumo propio». Luego añadió que «confitándolas con azúcar se conservarán largo tiempo»²2. Las recomendaciones de los tratadistas andalusíes y de fray Agustín constituyeron el corpus de conocimiento que los españoles disponían al trasladarse a América en general y al Reino de Chile en particular. Sobre esa base, y la experiencia en terreno, los fruticultores chilenos elaboraron su propio camino.

\footnotetext{
16 Ibidem: 158.

17 Ibidem: 144-145.

18 Ibidem: 126 y 132.

19 Agustín, 1617: 10; 116-118.

20 Ibidem: 121

21 Ibidem: 116.

22 Ibidem: 113.
} 


\section{Deshidratados en Chile y Cuyo: Huesillos, OREJONES E HigOS SECOS}

El duraznero crecía rápido y se adaptaba bien a los nichos ecológicos de Chile, pero su apreciada fruta presentaba un severo problema: una vez cosechada, era altamente perecible, por lo que duraba muy poco en buenas condiciones. Una semana después de cortada y sin sistemas de refrigeración, el durazno comienza a deteriorarse, por lo que se requería procesarlo para su conservación. Y esto fue justamente lo que desarrollaron los chilenos de la sociedad tradicional.

El procesamiento del durazno se realizó a través del orejón, el huesillo y el dobladillo. Un cronista describió estas modalidades en los siguientes términos: «secan muchos de estos, o enteros, quitada toda la piel, y entonces llaman huesillos, o divididos en tres partes, para solo secar el hueso, y entonces, llaman dobladillos, o hechos una tira y estos llaman orejones, de los que forman mazos» ${ }^{23}$. El orejón es el durazno deshuesado y seco; se parte al medio, se retira el carozo y se seca al sol. Con este proceso de deshidratación, se logra prolongar su conservación por varios meses, pero cumplido un año, ya sufre una desvaloración importante. Por su parte, el huesillo también es una deshidratación artesanal del durazno, pero sin retirar el carozo.

En las chacras chilenas era muy importante la actividad del secadero de frutas y se construían lugares especiales para la deshidratación de duraznos. Se usaba la firme madera de algarrobo y la más fina de canelo y arrayán. Andrés Aguirre y Francisca Ríos (San Felipe, 1795) tenían «una ramada que sirve para (secar) huesillos sobre 14 horcones de algarrobo» ${ }^{24}$. En el valle de $\mathrm{Pu}-$ taendo, don José Enríquez (1823) también tenía un espacio dedicado a secadero de duraznos y su construcción llamó la atención a los peritos tasadores que la registraron: «en una ramada de secar huesillos se hallan dos horcones de algarrobo útiles, 13 de madera blanca y tres varas de canelo, y 24 varitas de arrayán atravesadas ${ }^{25}$.

Para secar las frutas se utilizaban técnicas generales, pero adaptadas a las características de cada especie. El durazno se pelaba y se ponía a secar durante tres semanas. La ciruela, en cambio, no se pelaba; al conservar la cáscara, requería más tiempo para secarse (alrededor de 30 días). El huesillo se en-

23 Gómez de Vidaurre, 1780: 162.

24 Tasación y justiprecio de bienes de don Andrés Aguirre y doña Francisca Ríos. San Felipe, 3 de noviembre de 1795. Archivo Nacional (AN), Fondo Judiciales (FJ) de San Felipe (SFpe), legajo 1, pieza 28, folio $19 \mathrm{v}$.

25 Inventario de bienes de don José Enríquez, estancia de los Herrera, valle de Putaendo, 3 de setiembre de 1823. AN, FJSFpe, legajo 26, pieza 33, F. 9 v. 
vasaba en costales; por ejemplo en la residencia jesuita de La Selva, cerca de Copiapó (1767), se inventariaron «dos costales de huesillos secos de duraznos» ${ }^{26}$. Para los españoles del siglo XVIII, el costal era un «saco o bolsa grande, que se hace de xerga, lienzo u otro género, que sirve para echar en él trigo, cebada y otras muchas cosas, para llevarlas y transportarlas de una parte a otra» ${ }^{27}$.

La producción de estas conservas de duraznos generó un interesante desarrollo comercial para el mercado interno y para la exportación. Un cronista destacó que los huesillos y orejones «de toda suerte son un regalo manjar; y hacen un ramo de comercio con el Perú» ${ }^{28}$. En efecto, el durazno fue una de las frutas chilenas más tempranamente valoradas en el exterior. A mediados del siglo XIX, Chile exportaba 200 fanegas de huesillos, a \$7/fanega y 30.000 $\mathrm{kg}$ de orejones, a \$25 las 200 libras (Gay, 1855: 165). Mientras, la demanda en el mercado interno se mantenía elevada, pues sobre esta base se elaboró una bebida local: el mote con huesillo (durazno deshidratado, granos de trigo y jugo de durazno o ciruela). Esta tradición, proyectada hasta la actualidad, es muy popular en Chile.

Los orejones de durazno, al no tener carozos, eran más caros que los huesillos. Entre los bienes de don Tomás Córdoba (San Felipe, 1819), se registraron «4 almudes de orejones a 7 reales/almud, por ser del año anterior». El huesillo, más barato que el orejón, valía casi diez veces menos. Una fanega de huesillo se cotizaba alrededor de 10 reales, con variaciones según el tiempo y el lugar. En la casa de Juan Guzmán (San Fernando, 1807) se tasaron «3 fanegas de huesillos en 12 reales» ${ }^{29}$. En la chacra de doña María Magdalena Alzadora (San Felipe, 1818) se valoró «1 1/2 fanega de huesillo a 27 reales». Entre los bienes de la casa Gatica Hermanos (Santiago, 1847) se tasaron 18 almudes de huesillo a 2 reales/almud.

Las pomáceas se consumían preferentemente en fresco, pero las manzanas se guardaban para el invierno. En las zonas productoras se embalaban en cajones y se remitían a los mercados en carretas: «La manzana abunda y entre la gran variedad y diversidad que en ella se encuentra, se hallan muchas de un sabor y gusto exquisito. Esta fruta conservada viene más gustosa en la estación del invierno; y de algunos años a esta parte ha comenzado a ser un renglón no

${ }^{26}$ Inventario de bienes de los jesuitas en la residencia de La Selva, Copiapó, 4 de noviembre de 1767. AN, Fondo Jesuitas de Chile (FJCH), volumen 8, pieza 2, folio $152 \mathrm{v}$.

27 RAE, 1716: 640.

28 Gómez de Vidaurre, 1780: 162.

29 Tasación de bienes de don Juan Guzmán, Popeta, 8 de abril de 1807. AN, Fondo Judiciales de San Fernando (FJSFdo), legajo 41, pieza 5, folio 5. 
despreciable del comercio, especialmente en Mendoza, de donde bien acomodada en cajones, se conducen a otras provincias que carecen de ellas $\rangle^{30}$.

Los métodos de deshidratación también se usaron en las pomáceas, pero con menor frecuencia, pues estas frutas se conservan más tiempo que los carozos en forma apropiada: usando bien las técnicas tradicionales, se podían mantener en buenas condiciones hasta la siguiente primavera. Sin embargo, en algunos casos, se procedió también a la deshidratación, sobre todo para elaborar orejones de manzanas y membrillos. En una propiedad del Valle Central, a comienzos del siglo XIX, se registraron casos interesantes (Cauquenes, 1816); allí los notarios certificaron la existencia de 5 almudes de orejones de manzana y 5 fanegas con 10 almudes de orejones de membrillos. En ambos casos se estableció que el valor de tasación era de 1 real por almud, o bien de 12 reales por fanega de orejones, tanto de manzana como de membrillo. En la hacienda San Agustín de Chalinga (Santiago, 1847) se tasaron 5 almudes de orejones de membrillo a 4 reales/almud, 2 pesos, 4 reales. Los precios eran inferiores a los duraznos con igual preparación: como se ha señalado, el orejón de durazno valía 7 reales/almud, mientras que el orejón de membrillo oscilaba entre 1 y 4 reales/almud. Al parecer, el mercado valoraba más aquellos que estos, lo que explica la menor fabricación de orejones de manzanas y membrillos.

Por su parte, la higuera era interesante por sus dos tipos de frutos: el higo y la breva. En el Reino de Chile, la mayor parte eran de higo negro, pero también se cultivaron algunas de fruto blanco. Desde el punto de vista económico, la higuera también tenía un significado relevante. Según un tasador de la época, una planta grande producía higos por valor de 2 pesos por año ${ }^{31}$. Ello significaba un nivel equivalente al de los cítricos y ocho veces más alto que las frutas de carozo en general. Claudio Gay estimaba que «un árbol da 1 fanega y hasta $1 \frac{1}{2}$ ó 2 (fanegas) al año» $»^{32}$.

Los higos se podían consumir en fresco o se conservaban secos. Para secarlos, se extendían durante ocho días en ramadas, esteras o grandes piedras ${ }^{33}$. En el periodo estudiado, el valor de mercado de estas frutas deshidratada oscilaba entre 2 y 6 reales por almud. Al comenzar el siglo XVIII, en casa de don Martín de Rivera (La Serena, 1709), se tasó «1 fanega de higos a 6 reales el al-

30 Jesuita, 1787: 27

31 Tasación de bienes de la finca del callejón de Asola, de los finados Fuentes. Santiago, 15 de abril de 1849. AN, Fondo Judiciales de Santiago (FJStgo), volumen 388, pieza 14, folios 4 y 30 .

32 Gay, 1855: 166.

33 Ibidem: 166. 
mud $»^{34}$. Medio siglo más tarde, con el aumento de la producción, los precios bajaron. En la hacienda jesuita del valle del Elqui se tasaron «20 fanegas de higo a $\$ 3$ la fanega ${ }^{35}$. Proporcionalmente, ese precio significaba 2 reales el almud, o sea, una caída significativa. En el medio siglo posterior ese precio se mantuvo. Posteriormente, los precios repuntaron. En las haciendas de los citados hermanos Gatica (Santiago, 1847) se tasaron 25 almudes de higo a 4 reales/almud. Poco después se estimaba que el precio estaba en $\$ 5 /$ fanega $^{36}$. Los higos secos se envasaban en costales, igual que los huesillos de durazno y en el Reino de Chile aquellos valían 8 almudes cada uno. En la bodega de la hacienda jesuita Maitén, cerca de Copiapó (1767), se registraron «dos costales de higos secos»; y en su residencia se hallaron «treinta costales llenos de higos que, regulados lo que tiene cada costal de a ocho almudes, hacen veinte fanegas de dichos higos $\rangle^{37}$.

El higo seco era muy valorado en Chile, sobre todo en las capas populares y los sectores trabajadores, en especial entre los mineros del norte, pues completaba su dieta y servía como medio de pago. «Los peones y mineros (reciben) cada uno como 25 para su almuerzo. Por este motivo los hacendados del norte los cultivan en grande, sobre todo en el valle interior del Huayco y de Elqui $\rangle^{38}$. Asimismo, los higos secos y fraccionados en costales se destinaban a la exportación, llegando a figurar entre los principales productos que Chile vendía al exterior. A mediados del siglo XIX, se exportaban 80 fanegas al año, aunque con la fiebre del oro en California, se alcanzaron a exportar $3.000 \mathrm{fa}-$ negas ${ }^{39}$.

Además, los higos eran parte del patrimonio familiar y de la herencia. Cuando los vecinos del Reino de Chile redactaban su testamento, no dudaban en mencionar, entre sus bienes dignos de reconocimiento y transmisión, sus higueras. El caso de Polinarda Magdalena de Adecton (Parral, 1837) es ilustrativo del valor alcanzado por este frutal. En su testamento cedió a su sobrina María Luisa Troncoso «una piedra de moler, unas tijeras, una lupa, un manza-

34 Testamento de Martín de Rivera. La Serena, 1709. AN, Fondo Notarios de La Serena (FNLS), volumen 16, folio 61.

35 Inventario de bienes de la hacienda del valle del Elqui. La Serena, 5 de noviembre de 1767. AN, FJCH, volumen 5, pieza 4, folio 274.

36 Gay, 1855: 166.

37 Inventario de bienes de la hacienda nombrada Maiten en la villa del Guasco, Alto jurisdicción de la villa de San Francisco de la Selva, 9 de septiembre de 1767. AN, FJCH, volumen 8, pieza 2, folio $172 \mathrm{v}$. Inventario de bienes de los jesuitas en la residencia de La Selva, Copiapó, 4 de noviembre de 1767. AN, FJCH, volumen 8, pieza 2, folio $152 \mathrm{v}$.

38 Gay, 1855: 166.

39 Ibidem: 166. 
no más 17 matas de membrillo frutales, la mitad de una higuera, un peral frutal y un cuarto de la casa con puerta y candado que está al sur y un candelero» ${ }^{40}$. Es decir, los 17 membrillos, el peral y el cuarto de casa (con valor aumentado puesto que tenía puerta y candado), parecen términos equivalentes a la mitad de una higuera que Polinarda deja en herencia a su sobrina. Un caso parecido presenta el testamento de Pablo de Coria (Mendoza, 1762), quien entre vides y frutales consigna 1 higuera y media de su propiedad ${ }^{41}$.

\section{DULCES, JALEAS Y FRUTAS EN ALMÍBAR}

En Chile se elaboraron dulces y jaleas de fruta, además de fruta en almíbar. En las zonas rurales, estos productos se elaboraban para consumo doméstico. Pero poco a poco se comenzó a organizar una producción comercial orientada al mercado. En la ciudad de San Juan, en 1897, en el inventario y balance de bienes de don Juan Pío Radif, se constataron «27 maquinitas pesadas de pelar duraznos, 1 lote de tarros vacíos para conserva de duraznos usado y una prensa de prensar duraznos descarozados $\rangle^{42}$, entre otros implementos.

También en las tiendas de Santiago se podían comprar aquellos productos a comienzos del siglo XIX. Así quedó documentado, por ejemplo, en el negocio de don Marcelo Amaya. En el inventario de sus bienes, junto con otros productos alimenticios y del hogar, se registraron dulces de ciruela, durazno, guinda y peras, juntamente con cascos de cidro en almíbar. En este negocio había trece recipientes de dulce, jalea y almíbar de frutas, incluyendo tres de dulce de ciruela, dos de jalea de guindas, cinco de dulce de durazno, dos de dulce de pera y uno de cidro en almíbar. El dulce de ciruelas y la jalea de guindas se tasaban a $\$ 4$ con 4 reales por arroba, mientras que el de durazno se valuaba a $\$ 5$ por arroba. Los recipientes utilizados para conservar y comercializar los dulces, jaleas y frutas en almíbar eran ollas, tinajitas y cancos. No tenían medidas estandarizadas y en el marco de una producción todavía artesanal de envases, había grandes variaciones entre uno y otro. La capacidad de las ollas variaba entre una libra y una arroba con 16 libras; los cancos oscilaban entre 19 libras y dos arrobas con 18 libras (cuadro I).

40 Testamento de doña Polinarda Magdalena de Adecton, Parral, 1837. AN. Fondo Notarios de Parral (FNP), volumen 2, folio 402v.

41 Testamento de Pablo de Coria, Mendoza, 13 de agosto de 1762. Archivo Histórico de Mendoza (AHM), Protocolo n. ${ }^{\circ} 74$, folio 198v.

42 Inventario y balance general de los bienes de don Juan Pío Radif, según libros del mismo. San Juan, 22 de febrero de 1897. Archivo del Poder Judicial de San Juan (APJSJ), caja 31, 2. ${ }^{\circ}$ estante, Expte. 253, folios 41v-43 (Juan Pío Radif por quiebra 1899). 
CUADRO I. DULCES, JALEAS Y FRUTA EN ALMÍBAR EN VENTA EN LA TIENDA de don Marcelo Amaya. Santiago de Chile, 1812

\begin{tabular}{|c|c|c|c|c|}
\hline Fruta & $\begin{array}{c}\text { Tipo } \\
\text { de envase }\end{array}$ & $\begin{array}{l}\text { Peso neto } \\
\text { por envase }\end{array}$ & $\begin{array}{c}\text { Precio } \\
\text { por } @ \text { o libra }\end{array}$ & $\begin{array}{l}\text { Precio } \\
\text { neto }\end{array}$ \\
\hline Dulce de Pera & $\begin{array}{l}1 \text { canco } \\
1 \text { canco }\end{array}$ & $\begin{array}{l}2 @ 18 \text { libras } \\
2 @ 21 \text { libras }\end{array}$ & $\begin{array}{l}12 / 3 \mathrm{R} \times \text { libra } \\
13 / 4 \mathrm{R} \times \text { libra }\end{array}$ & $\begin{array}{l}\$ 5 \\
\$ 5\end{array}$ \\
\hline Almíbar de cascos de cidra & 1 canco & 19 libras & $2 \mathrm{R} \times$ libra & $\$ 5$ \\
\hline Dulce de Ciruela & $\begin{array}{l}1 \text { canco } \\
1 \text { tinajita } \\
1 \text { olla }\end{array}$ & $\begin{array}{l}4 @ 4 \text { libras } \\
1 @ 12 \text { 1/2 libras } \\
1 @ 12 \text { libras }\end{array}$ & $\begin{array}{l}\$ 41 / 2 \times @ \\
\$ 41 / 2 \times @ \\
\$ 41 / 2 \times @\end{array}$ & $\begin{array}{l}\$ 18 \mathrm{R} 5 \\
\$ 6 \mathrm{R} 6 \\
\$ 6 \mathrm{R} 6\end{array}$ \\
\hline Jalea de Guinda & $\begin{array}{l}1 \text { olla } \\
1 \text { olla }\end{array}$ & $\begin{array}{l}1 @ 5 \text { libras } \\
1 \text { libra }\end{array}$ & $\begin{array}{l}\$ 41 / 2 \times @ \\
11 / 2 \text { real } \times \text { libra }\end{array}$ & $\begin{array}{l}\text { \$ } 5 \text { R } 51 / 2 \\
\mathrm{R} 1 \frac{1}{2}\end{array}$ \\
\hline Dulce de Duraznito & $\begin{array}{ll}1 & \text { olla } \\
1 & \text { olla } \\
3 & \text { olla }\end{array}$ & $\begin{array}{l}1 @ 12 \text { libras } \\
1 @ 16 \text { libras } \\
1 \text { libra }\end{array}$ & $\begin{array}{l}\$ 5 \times @ \\
\$ 5 \times @ \\
2 / 3 \mathrm{r} \times \text { libra }\end{array}$ & $\begin{array}{l}\$ 7 \mathrm{R} 4 \\
\$ 8 \\
\mathrm{R} 2\end{array}$ \\
\hline
\end{tabular}

Fuente: Inventario y tasación de los bienes que quedaron por muerte de don Marcelo Amaya en la casa que fue de su morada. Santiago, 18 de febrero de 1812. AN, FJStgo, Legajo 45, Pieza 5, Foja 48.

\section{ACEITES DE OLIVA Y ALMENDRAS}

Los españoles desarrollaron una importante tradición en la elaboración de aceites, sobre todo de oliva. Los manuales de agricultura dedicaban un espacio considerable al manejo de los olivares, su cultivo y cosecha; seguidamente, entregaban recomendaciones precisas sobre la forma de elaborar y conservar el aceite de oliva, sin olvidar la lista de sus cualidades para la salud ${ }^{43}$. La temprana incorporación del olivo en Chile (segunda mitad del siglo XVI) y la buena adaptación a sus suelos y climas, despertaron grandes expectativas con respecto al desarrollo que podría alcanzar la industria aceitera en la región.

Sin embargo, el olivo presentaba la desventaja de demorar mucho tiempo en dar sus primeros frutos. Requería años de inversión y trabajo cultural antes de comenzar a producir. Esta situación desalentaba su cultivo. Muchos fruticultores tendían a priorizar plantas que alcanzaran la productividad más temprano, en dos o tres años. Con frecuencia, las precarias condiciones de vida de Chile tradicional, atentaban contra las inversiones de largo plazo. De todos modos y a pesar de este contexto relativamente desfavorable, se logró una ex-

43 Agustín, 1617: 122-124. 
pansión interesante del olivo en la región. Como se ha señalado al principio de este artículo, entre las 20 especies frutales cultivadas, el olivo estaba entre las cinco más importantes. Los registros identificaron 8.300 plantas, equivalentes al 7,6\% del total de la muestra. Con esta cantidad, el olivo se ubicaba entre las especies frutales cultivadas en forma abundante en la región.

El aprovechamiento del olivo no se orientaba al consumo en fresco. La única forma de poderse consumir la aceituna entera era mediante su preparación en salmuera. La alternativa era elaborar aceite de oliva. En ese contexto, los vecinos del Reino de Chile impulsaron varios establecimientos especializados, sobre todo en el norte, en la jurisdicción de La Serena. Ya en el siglo XVII existían molinos para elaborar aceite de oliva. En La Serena, don Blas Pizarro del Poso (1685) y don Francisco Núñez Galiano (1717) declararon entre sus bienes «un molino de hacer aceite y aceituna corriente» ${ }^{44}$.

Algunas mujeres detectaron una buena oportunidad en esta actividad. Doña Ana Granados fue una de las pioneras. En su chacra de La Serena, a comienzos del siglo XVIII, instaló un secadero de aceitunas y un molino de aceite, los que quedaron registrados en el inventario de bienes redactado al final de su vida. En primer lugar, ella secaba sus aceitunas en «un cuarto que sirve de ramada para secar aceituna, con enmaderación de sauce y cubierto de paja». Una vez fabricado el aceite, en «un molino de moler aceituna corriente», este se conservaba en tinajas de cerámica, que junto a las botijas estaban dedicadas a vino, mosto, aguardiente y vinagre; y entre ellas se detectó «una tinaja mediana para aceite» ${ }^{45}$.

Si bien el empuje de las mujeres contribuyó a impulsar la industria del aceite de oliva en Chile, esta actividad logró solo un desarrollo acotado en la región. Así lo consignó un observador a comienzos del siglo XIX al afirmar que con aceite de oliva «se sazonan muchas viandas, y se condimentarán muchas más si no supliera su falta, por costumbre del reino, la gordura derretida de las reses, que llaman grasa» ${ }^{46}$. Posteriormente, otro testimonio puntualiza que no obstante ser hermosos y abundantes los olivos y la cosecha de su fruto, el aceite que con sus olivas se fabrica es rancio, debido seguramente a la preparación descuidada de los campesinos ${ }^{47}$. En esta misma línea, Claudio Gay

44 Inventario de los bienes de don Blas Pizarro del Poso. La Serena, 28 de julio de 1685. AN, FNLS, volumen 12, folio 130v.; Testamento de Francisco Núñez Galiano. La Serena, 23 de octubre de 1717. AN, FNLS, volumen 19, folio 35.

45 Tasación de bienes de Ana Granados. La Serena, 4 de noviembre de 1728. AN, FNLS, volumen 3, folios 424, 425-425v y 427.

46 Pérez García, 1810: 21.

47 Poeppig, 1826: 137. 
destacó que el notable potencial que Chile tenía para desarrollar la industria del aceite no estaba suficientemente aprovechado:

Si Chile se dedicara con inteligencia á esta industria podría abastecer todos los países del Mar del Sur del aceite que se consume y que reciben de la Europa; pero el árbol es tardío en crecer, y solo da una regular cosecha á los 25 á 30 años, lo que es mucho para el Chileno siempre apresurado á coger los frutos de sus adelantos. Sin duda esto es el motivo de las pocas plantaciones que se hacen, satisfechos con los que existen para la fabricación del aceite necesario al país ${ }^{48}$.

Otro autor, en cambio, destaca que la industria del aceite de oliva no prosperó porque los chilenos preferían consumir las aceitunas de otra forma: «Gran parte de la aceituna que pudiera emplearse en aceite se destina a hacer de ella un manjar sumamente agradable y gustoso ${ }^{49}$.

Los chilenos también realizaron ensayos de elaboración de aceite de otras frutas. El caso más interesante fue un aceite de almendras registrado en Cauquenes (1814), donde doña María de los Ángeles Durán tenía «7 libras de aceite de almendra a $\$ 2$ la libra» ${ }^{50}$. El relevamiento documental no logró identificar más casos de elaboración de este producto, aunque no se han examinado todos los documentos existentes; además, no se hicieron inventarios de bienes de todas las propiedades. Por lo tanto, solo se registraba un pequeño porcentaje de los objetos realmente existentes. De ello se puede concluir que, posiblemente, existieron otros emprendimientos dedicados a elaborar aceites de almendras en el Reino de Chile. Pero se trataba de una actividad periférica dentro de la economía en general y del aprovechamiento de los frutales en particular.

\section{LAS MADERAS DE FRUTALES Y SUS DIFERENTES USOS}

En la medida que los árboles frutales envejecían y su producción caía por debajo de los costos, llegaba el tiempo de cortarlos para sustituirlos por una planta más joven y productiva. Se abrían entonces tres posibilidades de aprovechamiento de la madera: leña, construcción y ebanistería. Lo primero que se destaca del uso de la madera frutal, es la segmentación de usos según calidad del material. La madera de calidad inferior se usaba como leña. Le seguía en jerarquía aquella para enmaderar viñas (tutores y braceros). En tercer lugar estaba la madera para construcciones livianas, como las ramadas. En cuarto lu-

48 Gay, 1855: 149-150.

49 Jesuita, 1787: 29.

50 Tasación de bienes de doña María de los Ángeles Durán. Cauquenes, 20 de octubre de 1814. AN, Fondo Judicial Cauquenes (FJC), legajo 31, pieza 11, folio 14. 
gar se hallaban las maderas para construcciones de mayor categoría, como viviendas y bodegas.

La tradición de usar la madera de los frutales para construcción, carpintería y ebanistería, se remonta a los relatos bíblicos. En el templo de Salomón, la madera de olivo silvestre se utilizó para construir las puertas del santuario y la cornisa de la puerta de la nave ${ }^{51}$. Esa misma madera se empleó para los postes que guarnecían la entrada al Santa Sanctorum, y para los dos querubines de cinco metros de alto, recubiertos de oro, que lo adornaban ${ }^{52}$.

La cultura hispanoárabe ya había avanzado en la descripción y valoración de la madera de los árboles en general, y de los frutales en particular. Los tratadistas andalusíes realizaron una valoración comparativa de las distintas maderas, teniendo en cuenta tanto su dureza, consistencia y corteza. También examinan los usos de esas maderas. En el caso de los frutales, los estudios examinados se refieren casi exclusivamente a la calidad de la madera. Por lo general, se considera la madera frutal es de tipo mediano, salvo el caso del nogal, que se presenta como de mayor densidad. Los tratadistas árabes también consideraron los usos de la madera, y destacaron la importancia de algunas especias, sobre todo el álamo blanco (Populus alba), el álamo negro (Populus nigra), el sauce (Salix Alba) y el almez (Celtis Australis). Así, por ejemplo, la madera del álamo blanco y del álamo negro «es útil y se utiliza mucho en carpintería ${ }^{53}$. Además, para construir parrales, se utilizaba tanto la madera del álamo negro como la de sauce ${ }^{54}$. Mayor utilidad brindaba la madera de almez pues aportaba «para los materiales de las aceñas y molinas y para techas las casas. Esta madera, de gran calidad, tiene distintos usos, especialmente de carácter agrícola, empleándose sobre todo para fabricar coches o sillas de caballos y para armar parrales $\rangle^{55}$. En cambio, la madera de los frutales era muy secundaria. Los tratados andalusíes solo mencionan el caso de la madera del olivo silvestre: «su madera se emplea en la fabricación de aceñas porque es una de las más resistentes al agua junto con la de la encina y moralı ${ }^{56}$. Es importante aclarar que, en el contexto cultural dentro del cual se escribieron esos tratados, se entendía por aceña tanto el molino de agua como la rueda vertical del molino. Fuera de este uso, los tratadistas andalusíes no mencionan otro aprovechamiento de la madera de los frutales, como tampoco los tratados posterio-

51 I Reyes 6: 31-32.

52 Ibidem: 23-26.

53 Carabaza Bravo, García Sánchez et al., 2004: 110-111.

54 Ibidem: 108 y 111.

55 Ibidem: 84.

56 Ibidem: 294. 
res de Agustín (1617), Travanet (1848) y Sandalio Arias (1856). Por lo tanto, el capital cultural disponible en la sociedad hispano criolla del Reino de Chile, con respecto a las técnicas de aprovechamiento de la madera de los frutales, era mucho más acotado que en otros planos. A pesar de estas limitaciones, la abundancia de plantas frutales llevó a los moradores de esas tierras a encontrar la forma de aprovechar sus maderas de distintas formas.

La tradición hispano-árabe que se trasladó a América, señaló los usos que se podía hacer con la madera, pero sin la madera misma, salvo en el caso del sauce. En efecto, los vecinos del Reino de Chile disponían de sauces, particularmente de una variedad nativa, Salix humboldtiana Wild, también llamado Sauce chileno, Sauce amargo, Treique, Cheique o Reique. En cambio, ni el álamo ni el almez llegaron a Chile durante la dominación española. No tenemos noticias de la introducción del almez, mientras que el álamo llegó a la región ya iniciado el siglo XIX, en vísperas de la independencia. En efecto, en 1808, el español avecindado en Mendoza, don Juan Cobo, recibió de Cádiz ejemplares de dos variedades de álamo: Populus nigra y Populus fustigiata, y las cultivó en su propio huerto, con éxito. Las plantas se adaptaron satisfactoriamente a los suelos y climas cuyanos, y se propagaron velozmente porque fueron muy apreciadas por su madera. «De ahí su prodigiosa multiplicación que ha sido un ramo de riqueza para Mendoza y San Juan, donde no se tenían maderas de construcción, recibiéndolas a muy alto precio» ${ }^{57}$. Dos años después, en 1810, los franciscanos trasladaron el álamo de Mendoza hacia Chile, también con éxito ${ }^{58}$. La ausencia de maderas de construcción de fácil manejo, como el álamo y el almez, formuló un problema para la sociedad hispanocriolla del Reino de Chile. Y la solución, en buena medida, se encontró en la madera de los frutales.

La madera de los frutales fue muy valorada en el Reino de Chile como material de construcción y así figuraba en los inventarios de los corralones. En estos los tasadores identificaban y justipreciaban tanto la madera en bruto (troncos, ramas), como las que tenían algo de trabajo (palos, trozos) y hasta las que ya contaban con mayor nivel de preparación (horcones, tirantes, tijeras). La tasación dependía de la cantidad de material (número, dimensiones) y de su calidad, considerando además el trabajo agregado en su preparación. Los documentos entregan amplios detalles al respecto.

En la rica hacienda del sargento mayor don Juan Álvarez de Cortiñas (San Juan, 1757) se incluían «seis horcones de algarrobo y dos palos de peral, tasa-

57 Hudson 1898: 37.

58 Serra, Torres y Grez, 2002. 
dos en 5 pesos $»^{59}$. Don Francisco Serafín Toribio (San Felipe, 1806) tenía «veinte piernas de tijeras de 4 1/2 varas de largo, madera de peral canelo y patagua ${ }^{60}$. Entre los bienes de Domingo Funes (Mendoza, 1834) se anotaron «34 palos de peral de distintos gruesos, los que taso a tres reales» ${ }^{61}$. En el corralón de Pedro Valderrama (Mendoza, 1847) se hallaron «seis palos de peral mejores a 3 pesos y dos a 20 reales; uno de peral más delgado en 2 pesos; un trozo de peral como de 5 varas en 8 reales; 10 varillas de peral chuecas y delgadas a $1 / 2$ real» ${ }^{62}$. En la finca de María Francisca Pelliza (Mendoza, 1848) había «un palo de peral en pie, pero seco, en 40 centavos y dos palos de peral tuertos de 5 varas de largo en 50 centavos $\rangle^{63}$. En el inventario de bienes de Francisco Sales Torres (Mendoza, 1864) se menciona «un palo de peral labrado que ha servido de trasumbral en 12 reales» ${ }^{64}$.

El uso más básico de la madera se orientaba, entonces, a las viñas y parrales. Don Juan Videla y su esposa, Petrona Moyano (Mendoza, 1866), cultivaron un parral con 9 parras de moscatel y uva (negra), que incluía «24 horcones de guindo y peral que sostienen el embracerado, el cual se compone de 26 varillas de álamo» ${ }^{65}$. En la chacra de doña Mercedes Coó (Santiago, 1837), se usaban almendros para el enmaderado de los parrales ${ }^{66}$.

Después de la viña, la madera se destinaba a la construcción de las ramadas, corrales y soleras y la evidencia documental da cuenta de esta amplia difusión. Las ramadas servían para secar fruta, cubrir lagares y otras funciones; los corrales de alambiques se empleaban en la destilación de aguardiente y las soleras eran los aleros. Al tratarse de construcciones más livianas que las casas y bodegas, las ramadas, corrales y soleras se podían apoyar en horcones y ar-

59 Tasación de bienes de Juan Álvarez de Cortiñas, San Juan, 20 de setiembre de 1757. Archivo General de la Provincia de San Juan (AGPSJ), caja 9, carpeta 41, documento 5, folio $45 \mathrm{v}$.

60 Tasación de los bienes de don Francisco Serafin Toribio, San Felipe, 15 de julio de 1806. AN, FJSFpe, legajo 51, pieza 17, folio 8.

61 Inventario, tasación y partición de bienes de don Domingo Funes. Mendoza, 26 de agosto de 1834 . AHM, carpeta 19 , documento 9 , folio $7 \mathrm{v}$.

62 Inventario, tasación y división de bienes de Pedro José Valderrama. Mendoza, 27 de setiembre de 1847. AHM, carpeta 7, documento 4, folio 24.

63 Tasación de bienes de María Francisca Pelliza. Mendoza, 24 de noviembre de 1848. AHM, carpeta 42, legajo 16, folios 23 y 31v.

64 Inventario de bienes de Francisco Sales Torres. Mendoza, 28 de marzo de 1864. AHM, carpeta 56, documento 3 , folio 19 .

65 Inventario y tasación de bienes de Juan Videla y Petrona Moyano. Mendoza, 17 de agosto de 1866. AHM, carpeta 62, documento 4, folio 34v.

66 Inventario de Chacra. Doña Mercedes Coo con don Carlos Pérez sobre firma de inventario. Santiago, 1837. AN, FJStgo, legajo 264, pieza 2, folio 7v. 
cos de maderas menos duras. Por eso se empleaban otros frutales, como guindos, olivos, durazneros, ciruelos y almendros, además de los consabidos perales.

A fines del siglo XVIII en Curimón se registró una ramada sostenida con horcones de madera de guindo ${ }^{67}$. En su casa frente a la plaza de la ciudad de San Juan, doña Carmen Castro de Castro (1864) tenía, junto a los edificios principales, una ramada construida de la siguiente manera: «techada con despuntes de caña y formada en una muralla al norte de 20 tapias y siete adobones en tres corridas, siete horcones de algarrobo, uno de olivo y uno de peral, cuatro varillas álamo de solera, tres en el techo y tres de guarda patio; tasé en $\$ 30 »{ }^{68}$. En San Felipe se usó madera de durazneros para las ramadas, por ejemplo «el galpón sobre trece horcones de algarrobo y tres de durazno» de don Andrés Aguirre y doña Francisca Ríos (1795) y la «ramada que sirve para secar frutos, sostenida sobre catorce horcones rollizos, doce de ellos de algarrobo y espino y los otros dos de durazno, con 60 varas encima de canelo, arrayán y petra» de don Manuel Segura (1833) ${ }^{69}$. Por su parte, en la región cuyana, don Feliciano Sánchez tenía un «aparato de colgar carne, formado sobre tres horcones de algarrobo y tres ordinarios de durazno» ${ }^{70}$ (San Juan, 1862) y don José Clemente Benegas (Mendoza, 1834) poseía entre sus bienes «un arco grueso de durazno que importa $\$ 17$ que sostenía los pilares de adobe del corral de alambiques ${ }^{71}$. A mediados del siglo XIX se halló una casa de Santiago con soleras sostenidas por horcones de almendro ${ }^{72}$.

Siguiendo con la construcción de viviendas y bodegas, las paredes de los edificios, construidas con adobes, también se articulaban con horcones y tirantes de madera - que funcionaban como columnas - para formar una estructura flexible y resistente. Como se sabe, Chile y Cuyo son zonas sísmicas por excelencia y por ello las construcciones resultaban relativamente más adecua-

67 Partición de bienes de José Escobar. Curimón, 27 de julio de 1783. AN, FJSFpe, legajo 17 , pieza 10 , folio 11 .

68 A los acreedores de la testamentaria de doña Carmen Castro de Castro. San Juan, 20 de junio de 1864. APJSJ, caja 10, estante 1, expediente 91, folio $15 \mathrm{v}$.

69 Tasación y justiprecio de los bienes de don Andrés Aguirre y doña Francisca Ríos. San Felipe, 3 de noviembre de 1795. AN, FJSFpe, legajo 1, pieza 28, Foja 18. Tasación y partición de los bienes de José Manuel Segura (sucesión). San Felipe, 1833. AN, FJSFpe, legajo 49, pieza 7 , hoja 14 y $14 \mathrm{v}$.

70 Sesión de bienes que don Feliciano Sánchez hace a sus acreedores. San Juan, 6 de octubre de 1862. APJSJ, caja 33, 2. ${ }^{\circ}$ estante 269, folio 115.

71 Codicilo de José Clemente Benegas, Mendoza 5 de diciembre de 1834. AHM, Protocolo 213, folio 27.

72 Entrega de una finca. Santiago, 1847. AN, FJStgo, legajo 254, pieza 5, folio 66. 
das pues, salvo caso de terremotos muy fuertes, lograban una durabilidad apreciable dada la articulación flexible de materiales. En ese sentido, los frutales fueron el material más adecuado que los vecinos encontraron disponible para levantar sus casas y bodegas. La mayor parte de los horcones eran de algarrobo y espino; también se usaban de chañar, peral y, en algunos casos, de nogal.

En la finca de Juan Antonio Enríquez y Clara Silva (Putaendo, 1811), había un «rancho de la propia construcción alto y ancho que el antecedente, con 10 varas de largo, su horconada de peral, nogal y algarrobo con una puerta vieja tasé en 12 pesos»; y, años después, en la casa de José Enríquez (Putaendo, 1823 ) se registró «un ranchito que hace de cocina sostenido de cinco horcones de algarrobo y cumbreros de peral, y guioncitos de canelo, arrayán y sauce» ${ }^{73}$. Ignacio Ferramola y Candelaria Bargas (Mendoza, 1821) poseían «un galpón sostenido en tres horcones de 5 varas de alto: uno de algarrobo en 2 pesos, otro de chañar en 6 reales y otro de peral en 10 reales» ${ }^{74}$.

Pasando a la arquitectura destinada a la producción, la zona de lagares de la bodega de don Martín Oliva y doña Antonia Balmaceda (San Felipe, 1828) tenía dos horcones cumbreros de peral ${ }^{75}$. La bodega de Margarita Camus (Santa Rosa de los Andes, 1845) tenía una nave con forma de L, con 10 varas de largo en la extremidad corta y 15 de largo en el lado más largo, con 4 varas de ancho en ambos casos, donde se guardaba la vasija y los alambiques para aguardiente. El techo estaba cubierto de varilla y tejas y se apoyaba en una estructura de 41 viguetas de canelo y otras maderas, sostenidas «con horcones de peral y algarrobo» ${ }^{76}$.

Si los horcones servían de columnas, los tirantes funcionaban como vigas. Los vecinos de Chile y Cuyo los construían con madera de peral. José Simeón Moyano (Mendoza, 1834) poseía una bodega de dimensiones relativamente grandes (46 varas de largo por 6 de ancho y 5 de alto), cuyo techo tenía «42 tijeras de sauce rollizo, 23 tirantes de ciprés rollizo, que sirven de piso a la vivienda de arriba, ocho tirantes rollizos de peral y otras maderas en el resto de

73 Inventario de bienes de José Enríquez. Estancia de lo Herrera, Valle de Putaendo, 10 de setiembre de 1823. AN, FJSFpe, legajo 26, pieza 33, folio 9v.Tasación y partición de bienes de Juan Antonio Enríquez y doña Clara Silva. San Antonio de Putaendo, 17 de marzo de 1811. AN, FJSFpe, legajo 26, pieza 27, folio 4.

74 Inventario, tasación y partición de bienes de Ignacio Ferramola y Candelaria Bargas. Mendoza, 8 de marzo de 1821. AHM, carpeta 19, documento 6, folio 8 .

75 Inventario de bienes de don Martín Oliva y doña Antonia Balmaceda. San Felipe, 15 de julio de 1828. AN, FJSFpe, legajo 41, pieza 17, folio 22.

76 Inventario de bienes de Margarita Camus. Santa Rosa de los Andes, 10 de noviembre de 1845. AN, FJSFpe, legajo 21, pieza 25, folio 14. 
la bodega $\rangle^{77}$. La bodega de Mónica de la Cruz Pelliza (Mendoza, 1836) tenía «piso de terraplén, murallas de adobe y medio, cimiento doble de piedra, con $12^{3 / 4}$ varas de largo, 51/4 varas de ancho y alto, las murallas todas rebocadas. En su techo, dos tirantes de peral labrados con sus canes y 16 tijeras de sauce rollizas, caña y barro» y otros «dos tirantes de peral a 8 reales» ${ }^{78}$.

La madera de peral se utilizaba en la estructura de obra gruesa de las construcciones, es decir el armazón general de las viviendas o bodegas. Don José Muñoz (valle del Aconcagua, 1837) empleó esta técnica para uno de sus edificios: una "pieza de paja con un largo de $11 \frac{1}{3}$ varas, y ancho en su claro de ídem, sus murallas mixtas de tapial y adobe, en cinco armaduras de álamo y peral y al lado interior un corredorcillo sobre cuatro horcones de algarrobo, según su estado; taso todo en 22 pesos» ${ }^{79}$. La modesta casa de don Lorenzo Barahona y doña Andrea de la Torre (Río Claro, 1826) estaba construida con esta madera y los tasadores registraron «la casa principal de vivienda, la que se compone de 5 varas de largo, 3 de ancho, madera peral y sauce, muy ordinaria toda su fábrica, la que por lo muy mala tasamos en 12 reales» ${ }^{80}$.

Asimismo, la madera de peral se utilizaba para las terminaciones de carpintería, en particular los umbralados. En la casa de Juan del Canto (Santa Rosa de Los Andes, 1787) se registraron «diez umbraladitos de peral que aunque declara la señora haberlos labrado don Ignacio Ramírez su hijo, son de los perales de esta misma testamentaría $\rangle^{81}$. La bodega de don Lucas García (Mendoza, 1853) tenía «una puerta que mira al sur de 3 varas de alto y 2 de ancho, esqueleto y marco de sauce, umbrales de peral, en seis alcayatas y llave corriente» ${ }^{82}$.

En los documentos se registran puertas y ventanas fabricadas con madera de peral y nogal, en especial las terminaciones más finas, como balaustres, rejas, verjillas y marcos. En los salones de la estancia de San Juan de la Sierra (San Fernando, 1787) había una hermosa ventana que daba al patio, estaba construida con madera de ciprés y tenía tres corridas de siete balaustres cada

77 División y liquidación de bienes de José Simeón Moyano. Mendoza, 1 de setiembre de 1835. AHM, carpeta 33, documento 4, folio 12 .

78 Inventario, liquidación y división de bienes de Mónica de la Cruz Pelliza. Mendoza, 6 de junio de 1836. AHM, Época Independiente, testamentarías, carpeta 51, legajo 3, folios 3-3v.

79 Tasación de bienes de José Muñoz. Valle del Aconcagua, 14 de diciembre de 1837. AN, FJSFpe, legajo 36, pieza 6, folio 6v.

80 Inventario y tasación de bienes de don Lorenzo Barahona y doña Andrea de la Torre. Río Claro, San Fernando, 14 de abril de 1826. AN, FJSFdo, legajo 6, pieza 3, folio 4v.

81 Partición de bienes de don Juan del Canto. Valle de Santa Rosa, 16 de junio de 1787. AN, FJSFpe, legajo 10, pieza 1, folio 14.

82 Inventario de bienes de Lucas García. Mendoza, 13 de setiembre de 1853. AHM, carpeta 25 , documento 7 , folio 3 . 
una; en total, eran 21 balaustres de madera de peral ${ }^{83}$. En los edificios de la hacienda de don Gaspar de Herrera (Putaendo, 1798) se registró «una ventana de dos manos, de 1 1/4 varas de alto, con su correspondiente ancho, sus barrotes y verjilla de madera de nogal y peral $\gg{ }^{84}$. En San Juan de Pedegua, la casa de doña Francisca Navarrete de Guzmán (San Fernando, 1807) tenía una ventana con «reja de madera de peral, torneada» ${ }^{85}$. La bodega de Jacinto Godoy (Mendoza, 1850) tenía «dos puertas iguales de dos manos, de $2 \%$ varas de alto y $13 / 4$ varas de ancho, marco de peral, esqueleto de sauce y tableros de ciprés, clavados con clavos de hierro, pendiente en 6 alcayatas de flor y llaves corrientes» $^{86}$.

Finalmente, los muebles, utensilios del ajuar doméstico e imaginería religiosa también se fabricaron con madera de frutales: nogal, naranjo, damasco y, principalmente, peral. Entre los muebles hechos de peral, los más difundidos eran mesas y asientos. Las mesas podían ser redondas o rectangulares; los asientos eran sillas, taburetes o tablones. En la estancia de Limarí (La Serena, 1723) había dos escaños grandes de peral ${ }^{87}$. En el salón de la estancia San Juan de la Sierra (Colchagua, 1787), junto al estrado, había «seis taburetes, de madera de peral, ordinarios, con forro de badana vieja, su clavazón de tachuelas doradas»; cada uno se tasó a 10 reales, totalizando 7 pesos 4 reales $^{88}$. Casimiro Rodríguez (San Juan, 1838) tenía una mesa con armazón de sauce y tabla de peral, tasada en $31 / 2$ pesos $^{89}$.

Las terminaciones finas de algunos de estos muebles - en especial las patas torneadas - se hacían con madera de peral, lo mismo que los muebles destinados a guardar objetos de valor, como escritorios y cajas. En la casa de Juan Dionisio Henríquez (San Fernando, 1803) se registró «una mesa de peral, pies torneados con su cajón de 1 1/3 vara de largo, 1 vara de ancho y alto bien trata-

83 Tasación de bienes de Pedro José Guzmán. Estancia de San Juan de la Sierra, 12 de noviembre de 1787. AN, FJSFdo, legajo 24, pieza 2, folio 41v.

84 Inventario de bienes de Gaspar de Herrera. Valle de Putaendo, Jurisdicción de San Felipe, 12 de julio de 1798, AN, FJSFpe, legajo 26, pieza s/n, folios 2v-3.

85 Inventario y tasación de bienes de doña Francisca Navarrete de Guzman. San Juan de Pedegua, 28 de febrero de 1807. AN, FJSFdo, legajo 50, pieza 6, folio 44.

86 Inventario de bienes de Jacinto Godoy. Mendoza, 19 de febrero de 1850. AHM, carpeta 24 , documento 10 , folio 19 .

87 Inventario de bienes del maestre de campo Bartolomé Pastene. Estancia Limarí, La Serena, 30 de junio de 1723. AN, FNLS, volumen 13, folio 284.

88 Inventario de bienes de Pedro José Guzmán. Estancia de San Juan de la Sierra, 15 de noviembre de 1787. AN, FJSFdo, legajo 24, pieza 2, folios 6-6v.

89 Sesión de bienes de Casimiro Rodríguez. San Juan, 16 de agosto de 1838. APJSJ, caja 30 , estante 3 , folio 5 . 
da» y otra mesa de peral «pequeña, redonda, con cajón, sus pies torneados, bien tratada»; además de «un escritorio tallado, de peral; su largo 4/8 y 1/2, su ancho y alto $1 / 3$, con sus dibujos por adentro de concha de perla, con ocho cajones. Su chapa, llave y abrazaderas de fierro, todo nuevo» ${ }^{90}$.

La familiaridad de los fruticultores con la madera de peral les permitió aprovecharla para las actividades domésticas y otros fines, por ejemplo adornos. Doña Francisca Navarrete de Guzmán (Pedegua, San Fernando, 1807) tenía «un cucharón grande de peral»»1. En la tienda de Ramón Bravo (San Fernando, 1827) había una tijera de peral en 2 reales. Don Manuel José García (Mendoza, 1838) poseía «un cuadro con el retrato del general San Martín, de poco más de $1 / 2$ vara, marco de peral, con media caña dorada, en 12 reales $\rangle^{92}$. En la casa de José Manuel Funes (Mendoza, 1853) se registró «un mortero de peral con mano en 60 centavos» ${ }^{93}$.

La madera de peral también velaba el sueño de los fruticultores. Con ella construyeron muebles de dormitorio, como camas y cunas, y los delicados ornamentos de sus habitaciones; por ejemplo Margarita Tello (San Felipe, 1726) tenía «una cama con dos colchones, dos sábanas, dos almohadas, frazada de Castilla, dos sobrecamas (una de bordillo de algodón y otra hechiza de colores nueva), un pabellón nuevo y cuja de peral torneada maltratada $\rangle^{94}$. Entre los bienes del viticultor y bodeguero don Juan de la Cruz Cabrera (Curimón, 1799) se registraron «tres cujas de madera de roble y peral inconclusa ${ }^{95}$. Juan Dionisio Henríquez (San Fernando, 1803), por su parte, poseía «una cuna de peral, bien tratada, de $1 \frac{1 / 4}{4}$ vara de largo y $1 / 2$ vara de alto y ancho con los pilares torneados», y otros detalles de esa madera como «un dosel de patagua y la cenefa grabada de peral de 1 vara de alto» ${ }^{96}$.

Después de los perales, la madera frutal más utilizada en ebanistería fue la de nogal, en particular en la fabricación de puertas y ventanas finas, decoradas

90 Inventario de bienes de Juan Dionisio Henriquez. San Fernando, 8 de junio de 1803. AN, FJSFdo, legajo 43, pieza 3, folios 15v-16.

91 Inventario y tasación de bienes de doña Francisca Navarrete de Guzman. San Juan de Pedegua, 28 de febrero de 1807. AN, FJSFdo, legajo 50, pieza 6, folio 47v.

92 Inventario, tasación y división de bienes de José Manuel García. Mendoza, 15 de diciembre de 1838, folio s/n, Item 288.

93 Inventario y tasación de bienes de José Manuel Funes. Mendoza, 22 de junio de 1853. AHM, carpeta 20, documento 4, folio 16 .

94 Inventario de bienes de doña Margarita Tello. San Felipe, 29 de julio de 1726. AN, FJSFpe, legajo 10 , pieza 1 , folio $68 \mathrm{v}$.

95 Inventario de bienes de Juan de la Cruz Cabrera. Curimón, 10 de setiembre de 1799. AN, FJSFpe, legajo 10, pieza 24, folio 2.

96 Inventario de bienes de Juan Dionisio Henríquez. San Fernando, 8 de junio de 1803. AN, FJSFdo, legajo 43, pieza 3, folio 16v. 
con torneados y tallados. En Santiago (1804) se registró un «bufete de madera de nogal $\rangle^{97}$. En San Felipe (1814) se identificaron bancas de nogal y una puerta de nogal valuada en $\$ 12$ con «barras caladas y balaustres torneados de madera de nogal» ${ }^{98}$. En San Juan de Pedegua, San Fernando, la casa de doña Francisca Navarrete de Guzmán (1807) tenía «nueve taburetes de madera de nogal forrados con cojincillo de badana y tachuela de fierro ${ }^{99}$. Siempre en la zona de Colchagua, doña Ana María Jaramillo (1808) tenía «una docena de tabiques de madera nogal aforrados en badana a 12 reales; [en total] son 18 pesos y una vara de nogal de media (vara) en 4 reales $\rangle^{100}$. Pero la calidad de la madera de nogal fue valorada más allá de las fronteras de Chile, en particular Perú, generando las condiciones para su exportación. En determinado momento se estimó que la madera de nogal era una de las tres principales exportaciones de Chile hacia Lima ${ }^{101}$.

A uno y otro lado de la Cordillera, los ebanistas también usaron la madera de damasco. El jesuita de Mendoza destacó «que en el torno y bien bruñida descubre la variedad de vetas y colores que dan a la vista en su superficie en objeto tan variado y vistoso como el que representa a los ojos el más perfecto y labrado Jaspe» ${ }^{102}$. En Mendoza, don José Albino Gutiérrez (1831) tenía «un par de mesas de arrimo, madera de albaricoque con cuatro pies torneados, cubierta de doblar en $\$ 24$; un sofacito madera de albaricoque, asiento y respaldo de almohadón y movedizas en $\$ 10$; dos mesas madera de albaricoque embetunadas de cuatro pies torneados y cubiertas de doblar en $\$ 24 \gg^{103}$. En los testamentos de Manuela Maturana se registra «un bufete alto con su cubierta de tablas de patagua, sin cajón y los pies de madera de albaricoque» (Colchagua, 1829) y en el de José Joaquín Bezanilla, «una mesa de 11/2 varas con su cajón; y 10 taburetes sin forro, hechura antigua» (Santiago, 1823) ${ }^{104}$. Por su parte,

97 Inventario y tasación de bienes de Manuel Fernández Tobilla. Santiago, 18 de julio de 1804. AN, FJStgo, volumen 352, pieza 1, folio 7.

98 Inventario de bienes de José Ignacio de Herrera. San Felipe, 1814. AN, FJSFpe, legajo 26, pieza 28, folio 38. Doña Petronila Colarte con los acreedores de su marido Javier Goicoechea sobre derecho a un sitio, San Felipe, 19 de junio de 1814. AN, FJSFpe, legajo 11, pieza 12 , folio $5 \mathrm{v}$.

99 Inventario y tasación de bienes de doña Francisca Navarrete de Guzmán. San Juan de Pedegua, 28 de febrero de 1807. AN, FJSFdo, legajo 50, pieza 6, folio 50.

100 Partición de los bienes de doña Ana María Jaramillo, 1808. AN, FJSFdo, legajo 49, pieza 1 , folios 3 y 6 .

101 Carvallo y Goyeneche, 1876: 207.

102 Jesuita anónimo, 1787: 27.

103 Testamentaría de José Albino Gutiérrez. Mendoza, 19 de octubre de 1831. AHM, carpeta n. ${ }^{\circ} 23$, documento n. ${ }^{\circ} 1$, folios $32 \mathrm{v}$ y 33 .

104 Inventario y partición de los bienes de doña Manuela Maturana. Boldumaguida, Villa 
doña Francisca Pelliza (Mendoza, 1848) poseía una cómoda de albaricoque valuada en $\$ 25^{105}$. En San Fernando y Santiago (Chile) esta madera fue requerida para los muebles de dormitorio, como camas y sus respaldares y catres; así consta en los bienes declarados de don Domingo de la Arriagada (1788) y del mencionado José Joaquín Bezanilla ${ }^{106}$.

El mundo colonial valoró especialmente la madera de naranjo para fabricar muebles finos, es decir piezas de belleza y alto valor económico; razón por la cual también fueron escasos, por ejemplo en San Felipe (1819) se registró una escribanía de naranjo ${ }^{107}$. Por su parte, la imaginería religiosa se nutrió de esta madera para la elaboración de íconos. Los santos de madera de naranjo eran muy reconocidos y se tallaban a partir de troncos grandes para luego entregarse al culto. Hubo íconos de madera de naranjo que alcanzaron cierta popularidad entre los devotos. Sobre la base de estas costumbres se difundió una especie de oración, una forma especial de dialogar con los santos desde una posición de mayor confianza; sobre todo entre los viejos feligreses que alcanzaron el proceso completo, incluyendo la metamorfosis del árbol en ícono. Cuando los devotos necesitaban un favor difícil de conseguir y se les terminaban los recursos ordinarios, apelaban a expresiones alternativas, que no invocaban tanto a los procedimientos religiosos, sino a la cercanía material con el santo. De allí la expresión «te conocí naranjo», ampliamente difundida tanto en Argentina como en Chile. En una reciente recopilación de refranes populares, la frase se atribuye como originaria de un pueblito español ${ }^{108}$. Sin embargo, los naranjos fueron importantes no solo por los santos que efectivamente se tallaron y fueron objeto de culto, sino también por los relatos, poemas, cuentos y hasta refranes populares que circularon en torno a ellos. Un buen ejemplo es el cuento de Draghi Lucero, El santo del naranjo (1940), que es un reflejo de los criterios que la sociedad tradicional de la zona estudiada tenía con respecto a la potencial utilidad de la madera de los frutales en general y de los naranjos en particular.

de San José de Buena Vista, provincia de Colchagua, 12 de marzo de 1829. AN, FJSFdo, legajo 62, pieza 7, folio 16v; Inventario de los bienes de don José Joaquín Bezanilla. Santiago de Chile, 1823. AN, FJSgo, legajo 151, pieza 2, hoja 1.

105 Testamentaría de María Francisca Pelliza de Villanueva. Mendoza. 21 de noviembre de 1848. AHM, carpeta n. ${ }^{\circ} 42$, legajo n. ${ }^{\circ} 16$, folio 31.

106 Compromiso entre los herederos de doña Rosa de Alcalde. Santiago, 5 de diciembre de 1816. AN, FJSgo, legajo 21, pieza 2, hoja 5; Inventario de los bienes de don Domingo de la Arriagada. San Fernando, 1788. AN, FJSFdo, legajo 25, pieza 1, folio 20.

107 Tasación y justiprecio de los bienes de Carlos José Morales. San Felipe, 16 de octubre de 1819. AN, FJSFpe, legajo 33, pieza 33, folio 4.

108 Cambaceres, 2005: 39. 


\section{CONCLUSIÓN}

En el aprovechamiento de las plantas frutales hubo continuidades y cambios entre el proceso hispano-árabe de la península ibérica, y el camino hispanocriollo del Reino de Chile. En la industria conservera y aceitera hubo cierta continuidad de una región a otra; se aplicaron conocimientos equivalentes, con resultados relativamente homólogos. En cambio en el uso de las maderas hubo diferencias mayores, sobre todo porque las plantas que en España se usaban para construcción y carpintería no llegaron a Chile durante el periodo colonial.

La elaboración de conservas, aceites y maderas permitió un aprovechamiento intensivo de las plantas frutales durante los primeros siglos de la historia de Chile y Cuyo. De esta manera se hizo posible la expansión del cultivo de los frutales en Chile. En la industria conservera, la tradición hispanoárabe fue un aporte considerable para el desarrollo de la actividad en Chile. Sin embargo, los usos y costumbres locales marcaron una diferencia notable, como se refleja en el caso de los duraznos. Como se ha señalado, los tratados andalusíes recomendaban deshidratar el durazno cortado en partes y descarozado. Sin embargo, en Chile se hizo de un modo distinto y en magnitudes notables. En efecto, el producto más importante fue la elaboración de duraznos deshidratados con carozo, conocidos en Chile como huesillos. Este producto alcanzó una expansión notable debido a su aceptación y popularidad. Se exportaban cantidades significativas al Perú, aunque el principal consumidor era el mercado interno. Este fue el motor de la expansión de la fruticultura especializada en durazneros y el fundamento del auge de este cultivo: no fue casualidad que sobre 110.000 plantas frutales, se cultivaran 40.000 durazneros, equivalentes al $36 \%$ del total de los frutales de Chile y Cuyo. La expansión de esta actividad tuvo su influencia en el paisaje rural chileno, con la proliferación de las ramadas, que eran construcciones livianas dedicadas al secadero de estas frutas y su conservación.

Después de los huesillos, la industria conservera desarrolló otros productos interesantes: higos y ciruelas secos fueron los más relevantes. Estos productos seguían en cierta medida, la tradición andalusí. Le seguían en importancia los orejones de peras y manzanas, aunque en cantidades muy inferiores. También se logró desarrollar la elaboración de dulces y jaleas de ciruela, guinda, durazno y pera; los cidros, en cambio, se preparaban en almíbar. Inicialmente estos productos se elaboraban para consumo doméstico. Pero, poco a poco, se fue construyendo un mercado y se puso en marcha la producción con fines comerciales. La evidencia documental demuestra que a comienzos del siglo XIX ya se comercializaban estos productos en Santiago. 
Una mención especial merece la industria aceitera. El aporte de la tradición musulmana en este plano es notable, debido a las dimensiones que alcanzó esta actividad en el sur de España. Los árabes se interesaron en la elaboración de aceites de almendra y, sobre todo, de oliva. Estos conocimientos se trasladaron al Reino de Chile, donde se intentaron llevar a la práctica, pero con resultados modestos. Los altos costos de producción y la relativa pobreza del mercado interno determinaban los límites a la expansión de la olivicultura chilena. A pesar de ello los chilenos lograron poner en marcha la olivicultura y la industria aceitera en forma lenta, pero constante. El olivo fue uno de los seis frutales cultivados en forma abundante en Chile y, sobre esta base, se logró construir una promisoria tradición de aceite de oliva. A mediados del siglo XIX los niveles de producción eran todavía modestos. Pero ya se había transitado un camino interesante. En forma complementaria, pero en cantidades muy inferiores, se detectó también la elaboración de aceite de almendra.

El aprovechamiento de la madera de los frutales fue una innovación relativamente original de los chilenos, debido en buena medida, a la ausencia de las plantas que habitualmente se usaban como madera en el sur de España (álamo y almez). En estas condiciones, los grupos humanos se adaptaron a estas circunstancias y utilizaron en Chile la madera de los frutales, para los mismos fines que en España se usaba la madera de otras plantas. De acuerdo a sus condiciones, las maderas de frutales se destinaban para distintos fines. Las de calidad inferior se empleaban para enmaderar viñas y parrales. Con madera de guindo y almendro se fabricaban los medios de sostén y conducción de las cepas, sobre todo tutores, horcones y braceros. También se usaba madera de frutales para la industria de la construcción. Las instalaciones livianas, como ramadas, corrales y soleras (aleros) se manufacturaban, principalmente, con madera de duraznero, además de usarse madera de guindo, olivo, peral, ciruelo y almendro. Para construcciones más importantes, como viviendas y bodegas, se utilizaban horcones y tirantes de peral y, en algunos casos, nogal. Lo mismo ocurría con las terminaciones de carpintería de las casas: el peral estaba muy presente en puertas y ventanas, umbralados y rejas.

Saliendo del plano de la carpintería y entrando en la ebanistería, la madera de frutal se utilizó en la fabricación de muebles, utensilios del ajuar doméstico y en la imaginería religiosa. La madera de peral fue ampliamente utilizada para fabricar mesas y sillas, taburetes y bancos, camas y cunas, escritorios y cajas. También se empleó para utensilios domésticos como cucharas, tijeras y morteros. Además, se usaron otras maderas frutales para muebles finos, sobre todo de nogal, damasco y naranjo. Este último se utilizó también para imaginería religiosa. 
La modesta madera de peral fue la más usada de todos los frutales. Tuvo una función importante, sobre todo entre los campesinos pobres. Se aplicó tanto en construcción de casas y bodegas (horcones y tirantes), como en carpintería (puertas, ventanas, umbralados) y en ebanistería (muebles y utensilios). Le seguían en importancia las maderas de duraznero (para horcones de ramadas) y nogal (para construcción, carpintería y ebanistería). En un tercer nivel seguían otras maderas como guindo (viñas), almendro (viñas y soleras), damasco (ebanistería) y naranjo (ebanistería e imaginería religiosa).

Muchas de estas actividades agroindustriales han perdido continuidad en el tiempo. La madera de frutal ya no ocupa un lugar relevante en Chile, debido a las ventajas de otras provenientes de árboles forestales. Lo mismo puede decirse de las frutas secas. En las últimas décadas, esas actividades tradicionales han retrocedido y el fuerte de la fruticultura chilena está orientado hacia la producción y exportación de fruta en fresco. Ello es posible debido a la disponibilidad de equipamiento e instalaciones adecuadas para la conservación y transporte en frío. Pero lo importante de la experiencia aquí rescatada es que, gracias al aprovechamiento examinado, fue posible la expansión de la fruticultura en Chile durante tres siglos. De esa forma se construyó la base cultural para la posterior expansión de la actividad.

Además, la experiencia examinada tuvo efectos sociales en la región. El sistema impuesto por las grandes potencias europeas a sus colonias tendía a difundir el latifundio, la actividad agropecuaria extensiva y la producción de materias primas para exportación. A pesar de ello, en Chile fue posible desarrollar, al menos en forma acotada, una interesante experiencia de agricultura intensiva orientada al mercado interno. Ello fue factible por el desarrollo de la actividad agroindustrial que permitía un aprovechamiento de las frutas y maderas de esos frutales. De esta manera, se promovió un proceso de diversificación económica, con una actividad de mayor valor agregado y movilidad social, a la vez que generó las condiciones para matizar la hegemonía de la cultura de la renta, mediante actividades orientadas a la cultura del trabajo. En este contexto, la agroindustria contribuyó a construir los cimientos de una actividad que, una vez generadas las condiciones técnicas adecuadas, permitiría a Chile convertirse en potencia fruticultura de nivel mundial.

\section{REFERENCIAS BIBLIOGRÁFICAS}

Agustín, Fray Miguel de (traductor al español), Libro de los secretos de la agricultura, casa de campo y pastoril (1617), Barcelona, Imprenta de Juan Piferrer, 1722. Edición facsimilar: Valladolid, Maxtor, 2001. 
Alonso Millán, Jesús, «Algunas conexiones ecológicas entre Iberoamérica y Europa, 1810-2010», revistaambienta.es/WebAmbienta/marm/Dinamicas/secciones/articulos/millan.htm.

Amaral, Samuel, «Comercio libre y economías regionales. San Juan y Mendoza, 1780-1820», Jahrbuch für Geschishte von Staat, Wirtschaft und Gesellschaft Lateinamerikas, 27 (Böhlau Verlag Köln Wien, 1990), 1-67.

Braudel, Fernand, La identidad de Francia [1986], Barcelona, Gedisa, 1993.

Cambaceres, Eugenio, Música sentimental, Buenos Aires, Stokcero, 2005.

Carabaza Bravo, J.; García Sánchez, E.; Hernández Bermejo, E. y Jiménez Ramírez, A., Árboles y arbustos de Al-Andalus, Madrid, CSIC/Estudios Árabes Islámicos, 2004.

Chevalier, François, «La formación de los grandes latifundios en México», Problemas agrícolas e industriales de México, 8, 1 (México, marzo 1956): 1-256.

Coria, Luis Alberto, «El boom vitivinícola mendocino y su impacto espacial interno», Estudios Avanzados, 14 (2010): 145-174.

Corona Páez, Sergio, La vitivinicultura en el pueblo de Santa María de las Parras. Producción de vinos, vinagres y aguardientes bajo el paradigma andaluz (siglos XVII y XVIII), Torreón, Ayuntamiento de Torreón, 2004.

Crosby, Alfred (1986), Imperialismo ecológico. La expansión biológica de Europa, 900-1900, Barcelona, Crítica, 1988.

Draghi Lucero, Juan, «Árbol castigado», Juan Draghi Lucero, Antología de Cuentos, Mendoza, Zeta, 1996: 201-206.

Gay, Claudio, Agricultura chilena, París / Santiago de Chile, Museo de Historia Natural, 1855. Edición moderna consultada: Santiago de Chile, Icira, 1973.

Gligo, Nicolo y Jorge Morello, «Notas sobre la historia ecológica de América Latina», Estudios Internacionales, 13, 49 (Santiago de Chile, ene.-mar., 1980): 112-148.

Gligo, Nicolo, La dimensión ambiental en el desarrollo de América Latina, Santiago de Chile, NU-CEPAL, 2001.

Gómez de Vidaurre, Felipe, Historia geográfica natural y civil de Chile, Santiago de Chile, Ercilla, 1780.

Halperín Donghi, Tulio, Historia contemporánea de América Latina, Madrid, Alianza, 2008.

Hernández, Alicia y Ruggiero Romano, Por una historia de América Latina, México, FCE, 1999.

Hudson, Damián, Recuerdos históricos sobre la Provincia de Cuyo [1898], Mendoza, EDIUNC, 2008. 
Jesuita Anónimo (1787), Fuente Americana de la Historia Argentina, Descripción de la provincia de Cuyo. Cartas de los jesuitas Mendocinos, Mendoza, Best Hermanos, 1940.

Lacoste, Pablo, «Viticultura y movilidad social: provincia de Cuyo, Reino de Chile, siglo XVIII», Colonial Latin American Historical Review, 13, 3 (2004): 217-248.

Lacoste, Pablo, «Complejidad de la industria vitivinícola colonial: crianza biológica de vinos (Reino de Chile siglo XVIII)», Latin American Research Review, 42, 2 (Austin, Texas-June, 2007): 157-171.

Lacoste, Pablo, «Wine and woman: grape growers and pulperas in Mendoza (1561-1852)», Hispanic American Historical Review, 18, 3, 2008: 361-392.

Lacoste, Pablo, La mujer y el vino: emociones, vida privada, emancipación económica, Mendoza, Caviar Bleu, 2008: 307.

Mellafe, Rolando (1981), «Latifundio y poder rural en Chile de los Siglos XVII y XVIII», Cuadernos de Historia, 1 (Santiago, diciembre 1981): 87-108.

Melville, G. K., Plaga de ovejas. Consecuencias ambientales de la conquista de México, México, FCE, 1999.

Mennell, Stephen, Francais et anglais a table du moyen age a nos jours (1985), France, Flammarion, 1987.

Meyzie, Philippe, L'Alimentation en Europe a l'époque modern. Manger et boire $X V I^{e}-X I X^{e}$ S., Paris, Armand Colin, 2010, Melville (1999).

Mishkin, David Joel, The American Colonial Wine Industry. An economic interpretation, New York, Arno Press, 1975.

Muñoz Correa, Juan Guillermo, «Las viñas y el vino de Colchagua en el siglo XVII», Boletín de la Academia Chilena de la Historia, LXVII, 110 (Santiago de Chile, 2001): 165-204.

Pérez García, José Antonio, Historia de Chile, Tomo I, 1810, Colección de Historiadores de Chile y Documentos relativos a la Historia Nacional, tomo XXII, Santiago de Chile, Imprenta Elzeviriana, 1900.

Poepigg, Eduard, Un testigo en la alborada (1826-1829), Santiago de Chile, Zig-Zag, 1960.

Real Academia Española (RAE), Diccionario de Autoridades, Tomo I, Madrid, 1716. Edición facsimilar consultada: Madrid, Gredos, 2002.

Rice, Prudence, «La industria vitivinícola en Moquegua, Perú», Estudios Avanzados, 14 (2010): 29-62.

Rivera Medina, Ana María, Entre la cordillera y la Pampa: la vitivinicultura en Cuyo, Argentina (s. XVIII), San Juan, Editorial Fundación de la Universidad de San Juan, 2006. 
Sagredo Baeza, Rafael y José Ignacio González Leiva, La expedición Malaspina en la frontera austral del imperio español (1793), Santiago de Chile, Universitaria / DIBAM, 2004.

Sandalio Arias, Antonio, Novísima agricultura práctica, o sea, Manual del labrador, hortelano, jardinero y arbolista según los adelantos y la práctica de los más célebres agricultores nacionales y extranjeros, Madrid, Al libro de oro, 1856.

Serra, M. T.; Torres, J. y Grez, I., «Breve historia de la introducción en Chile del álamo [Populus nigra L. var. italica (Moench.) Koehne] y el desarrollo de ejemplares siempreverdes», Chloris Chilensis, 5, 2 (2002). URL: http://www.chlorischile.cl

Soldi, Ana María, «La vid y el vino en la costa central del Perú, siglos XVI y XVII», Universum, 21, 2 (Talca, 2006): 42-61.

Travanet, Scipion de, Catecismo de agricultura universal o sea, la agricultura enseñada por principios aplicados a la práctica de todos los lugares, Madrid, Imprenta de Santiago Saunaque, 1848. Traducción y adaptación de Pedro Martín de López.

Fecha de recepción: 4 de mayo de 2010

Fecha de aceptación: 28 de febrero de 2011

\section{Fruit trees and agro-industry: cans, oil and timber (Chile and Cuyo, 1550-1850)}

The rapid propagation of European fruit-bearing plants in Chile and Cuyo led to the problem of their exploitation, which was a complex issue in the period before the availability of means of refrigeration. The response was to encourage agro-industrial activity. Some fruits were conserved through a process of dehydration and others were used in the making of oils. Some of these products were commercialised on the domestic market and others were exported, especially to Peru. There was also an improved use of the timber from fruit trees in both the construction industry and carpentry and cabinet-making. These activities ensured the economic viability of fruit-growing and made it possible for it to expand in the region under analysis.

KEY WORDS: Agro-industry; fruit-growing; dried fruit; olive oil. 